\title{
Scaffolding of Learning in Library Makerspaces
}

Einarsson, Arni Már; Hertzum, Morten

Published in:

Proceedings of the FabLearn Europe 2019 Conference

DOI:

$10.1145 / 3335055.3335062$

Publication date:

2019

Document version

Peer reviewed version

Citation for published version (APA):

Einarsson, A. M., \& Hertzum, M. (2019). Scaffolding of Learning in Library Makerspaces. In Proceedings of the FabLearn Europe 2019 Conference [7] Association for Computing Machinery.

https://doi.org/10.1145/3335055.3335062 
Proceedings of the FabLearn Europe 2019 Conference (Oulu, FI, May 28-29), Paper 7. ACM Press, New York. Author version. Final version available at: https://doi.org/10.1145/3335055.3335062

\section{Scaffolding of Learning in Library Makerspaces}

\author{
Árni Már Einarsson \\ Dept. of Information Studies \\ University of Copenhagen \\ Copenhagen, Denmark \\ arni.mar.einarsson@hum.ku.dk
}

\author{
Morten Hertzum \\ Dept. of Information Studies \\ University of Copenhagen \\ Copenhagen, Denmark \\ hertzum@hum.ku.dk
}

\begin{abstract}
Makerspaces have spread to libraries in recent years, to promote equitable access to technologies, expand services, and encourage participation and learning. In this paper, scaffolding of learning is studied from the perspective of library makerspace practitioners. On the basis of interviews in six Danish libraries, we analyze formal, non-formal, and informal activities and identify seven ways of scaffolding. Three challenges are discussed: (a) fostering community while ensuring inclusion in informal activities, (b) avoiding to stifle creativity in short-term activities, and (c) finding the role of the library in formal activities. We propose actions to overcome these challenges, such as encouraging scaffolds across formal, non-formal and informal learning activities and addressing the educational role of the library.
\end{abstract}

\section{Author Keywords}

Makerspace, Scaffolding of learning, Participation, Library

\section{ACM Classification Keywords}

H.5.m. Information interfaces and presentation (e.g., HCI): Miscellaneous

\section{INTRODUCTION}

Makerspaces are emerging in diverse communities as a local space where individuals can meet, make, learn, and share [14]. Libraries are one of the institutions that have embraced these new spaces $[1,5,9,24,30,31]$. It has been argued that makerspaces and libraries are a natural combination because makerspaces in libraries offer "a framework by which shared core library and community values such as equitable access to information, resources, and opportunity for lifelong learning can be reconciled and amplified" [9:2990]. Yet, providing and equipping the space is not enough to create a successful makerspace. It is also necessary to invite activities that attract and sustain user interest and development. That is, it is necessary to scaffold learning.

Paste the appropriate copyright/license statement here. ACM now supports three different publication options:

- ACM copyright: ACM holds the copyright on the work. This is the historical approach.

- License: The author(s) retain copyright, but ACM receives an exclusive publication license.

- Open Access: The author(s) wish to pay for the work to be open access. The additional fee must be paid to ACM.

This text field is large enough to hold the appropriate release statement assuming it is single-spaced in Times New Roman 8-point font. Please do not change or modify the size of this text box.

Each submission will be assigned a DOI string to be included here.
Scaffolds seek to facilitate learning by constraining the possibilities for action [22]. To succeed, they must ensure low barriers to entry while, at the same time, providing the challenges necessary for long-term engagement. With too few constraints the possibilities may be vast but the barriers to participation are high because the users must themselves discover what is possible, bring the ideas, build the competences, overcome the setbacks, and so forth. With too many constraints the possibilities are too few, and user interest quickly dwindles. On the basis of interviews with representatives from makerspaces in six Danish public libraries, this study explores how learning is scaffolded and what challenges library makerspace practitioners experience in scaffolding learning activities. The investigated library makerspaces have activities for schools, families, as well as the general public. Directing the activities toward these different audiences means scaffolding them differently depending on the audience, thereby also creating a need for transparency about when different scaffoldings will be in effect.

In the following, we review related work on library makerspaces and scaffolding, account for our method and present the results of the interviews conducted. In the paper, we discuss three challenges, which concern defining the role of the library, ensuring inclusion, and avoiding to stifle creativity.

\section{RELATED WORK}

The spread and popularity of makerspaces have happened in less than two decades [9]. In a survey of public libraries in 31 large cities across the world Born et al. [5] find that $41 \%$ of the libraries have makerspaces. In addition, library makerspaces have spread to rural areas [1].

\section{Library makerspaces}

While individual instances of makerspaces can differ widely, the notion of a makerspace is an umbrella term for creative spaces such as hackerspaces and FabLabs "[..] where Makers congregate and, ideally, have access to the tools, spaces, and resources that help them create the things they Make" [30:2]. In spite of their variety the purpose of library makerspaces centers around similar goals [23]:

- To expand library services through additional offerings

- To foster community engagement and involvement

- To promote equitable access to technological tools

- To encourage participatory learning 
Pursuing these goals involves a belief that libraries should be more like kitchens and less like grocery stores [28]; that is, they should be places of creation rather than consumption. In this way, makerspaces contribute to the reorientation of libraries away from a mainly book-centered approach and to attracting new users and collaborators [15,23].

Makerspaces are believed to hold great potential for learning $[4,13,26]$. For example, research studies report that makerspaces "offer a safe space to design, create, fail and try again" [19], that the provision of a library makerspace "would be empowering" to its users [8], and even that the learning has an aspect of activism in that "makers aim to intervene to create a world different to the one we live in" [24]. However, Willett [28] strikes the cautionary note that it is often unclear whether the users of library makerspaces experience an urgent need to create, just as it mostly remains unspecified how the empowerment manifests itself. It has also been found that whereas failing epitomized learning in the eyes of makerspace mentors, the teenage users of the makerspace equated failing with not learning [7]. Specifically, many of the teenage users were disinclined to take on larger projects and, instead, preferred fast projects that fitted into 30-45 minute timeframes. Such brief timeframes left little time for failure and learning. Thus, a 'maker mindset' cannot be assumed. To attract and sustain broad interest in a makerspace, libraries must be prepared to cultivate such a mindset. Otherwise, library makerspaces may attract a fairly narrow group of users.

The maker movement emphasizes informal learning, sometimes to the extent of creating a polarization between hands-on, learner-led, playful, informal learning and instruction-style, tedious formal learning [28]. Many library makerspaces are, however, involved in educational activities with schools, either through a collaboration between a public library and a school or because the makerspace is part of a school library. In both cases, the makerspace hosts activities that are embedded in a formal-learning curriculum. As a commendable example, Thanapornsangsuth [25] shows how a four-day makerspace program engaged Indian eighth grade students (12-14 years old) in identifying and working to solve community problems. For example, one of the student groups created a prototype diffuser for lemongrass oil to keep mosquitos away. A key result of the study was the importance of purpose and passion in uniting the students around a group goal and in driving them to persist through challenges. However, the four-day program required a staff of 19 people to support the about 50 students. At the informal end of the spectrum, Taylor et al. [24] show that makerspaces may primarily be hubs of community. For example, the Westhill Men's Shed provided a communal workspace for older men with mental health issues. In these makerspaces the fabrication activities mainly serve as a scaffold for coming together, learning from each other, and socializing.

\section{Scaffolding}

The concept of scaffolding is rooted in constructivist learning theory [27] that conceptualizes learning as a mental adaptation that happens through mediated interactions with the external environment (the context). In constructivist learning theory, the mind and body are inseparable. Learning is entangled in the actions and activities performed [16]. In educational settings, the context consists of the learning objectives, mediating tools, formal and informal rules, community of people involved, and the division of labor among them. These elements define the activity system and structure the activity [16]. Though, individual's motivations, preferences, and history of learning influences the outcomes, the activity can be designed to scaffold towards specific learning objectives. The concept of scaffolding is connected to Vygotsky's idea of the zone of proximal development, that is, the distance between an individual's current level of development and the potential development level that can be achieved through guidance from educators or capable peers [27:86]. By activity design, material selection, temporal arrangements and guidance, certain actions are constrained while others are favored. In this way, scaffolds "structure human activity by supporting and guiding it, while at the same time configuring and disciplining it" [20:462]. That is, scaffolds in library makerspaces are the socio-material conditions that facilitate users at different levels of development in progressing and learning.

In makerspaces, scaffolding is important as the tools and space itself do not ensure the participation of new users $[2,10,24]$. To bridge these gaps, Dreessen and Schepers [10] propose five strategies for scaffolding participation by making activities that combine open-door access, short-term events, and long-term community building. On the interpersonal level, Thanapornsangsuth [25] studies groups going through a design process with 19 staff to support them in the zone of proximal development. The staff made it possible to make advanced solutions but at the risk of steering the groups toward the staff's ideas for solutions. Bowler and Champagne [7] argue for using eight activation questions that are sensitive to not stifling creativity. The questions include "Who is my audience?", "What resources do I have and need?", and "What kind of maker am I?" and are intended to create reflection and thereby help guide people's learning processes. The challenge of scaffolding in makerspaces is, on one hand, to structure and guide the activity while, on the other hand, not restricting the freedom of action and creativity too much [7].

Library makerspaces scaffold learning in formal, informal and non-formal activities. Formal learning activities are often pre-structured for a group of students in an educational institution [18]. Though there may be considerable room for student projects, temporal boundaries and instructional design contribute to structuring the formal activities. Several studies point to tensions between, on the one hand, curriculum planning and learning goals and, on the other hand, the interdisciplinary and exploratory aspects of 
learning in a makerspace [4,17]. However, curriculum planning and learning objectives scaffold learning in ways that help clarify to the students what and how to do. In contrast, informal learning is self-directed, incidental, and interest-driven [21]. It happens outside formal educational contexts and is structured around learner-initiated projects rather than pre-set educational objectives. Informal learning may be individual, but in relation to makerspaces its communal and social aspects are often emphasized to the point of being considered integral to it $[12,23]$. Scaffolds for informal learning should not prescribe activities or goals but rather map out the space of possibilities. Non-formal learning is a hybrid of formal and informal activities. Nonformal activities are structured or semi-structured, and they happen outside formal education [11]. Non-formal activities often take the form of events aiming to train specific competences [11] or inviting new users to makerspaces $[10,24]$. Consequently, scaffolds must strike a delicate balance between disciplining the activities and honoring interest-driven and self-motivated learning.

\section{METHOD}

To study the conditions for learning, we interviewed library makerspace practitioners about their formal, informal, and non-formal activities and how elements in the activity system [16] help scaffold learning. We conducted six semistructured interviews [3] with a total of nine library makerspace practitioners in six different public libraries. The interviews were conducted in person combined with a tour in

\begin{tabular}{|c|c|}
\hline Background & $\begin{array}{l}\text { What is your background and experiences in } \\
\text { the space? What is the history of this } \\
\text { makerspace? }\end{array}$ \\
\hline Tools & Can you show me around in the space? \\
\hline Activity & $\begin{array}{l}\text { What formal activities take place? What } \\
\text { organized events are facilitated? What informal } \\
\text { uses are there of the makerspace? }\end{array}$ \\
\hline $\begin{array}{l}\text { Users } \\
\text { (subjects) }\end{array}$ & $\begin{array}{l}\text { What users are targeted, implicitly and } \\
\text { explicitly? What users and groups use your } \\
\text { makerspace? Are any users favored over } \\
\text { others? }\end{array}$ \\
\hline Community & $\begin{array}{l}\text { How is the makerspace connected to the } \\
\text { library? } \\
\text { How is the makerspace connected to the other } \\
\text { organizations/groups (e.g., hobbyists, local } \\
\text { companies, schools and municipalities)? } \\
\text { Are there any conflicts in the audience? If so, } \\
\text { how has the makerspace adjusted? }\end{array}$ \\
\hline Rules & $\begin{array}{l}\text { What are your policies on access? What are } \\
\text { your policies on the use of tools and materials? } \\
\text { How are the policies enforced? }\end{array}$ \\
\hline Roles & $\begin{array}{l}\text { What skills are required in a library } \\
\text { makerspace? } \\
\text { What is there required of users and volunteers? }\end{array}$ \\
\hline Object & What is the purpose of the makerspace? \\
\hline Outcome & $\begin{array}{l}\text { How well do you think the makerspace achieves } \\
\text { its purpose? }\end{array}$ \\
\hline
\end{tabular}

Table 1. Interview guide the makerspace. The library makerspaces were spread across four of the five regions in Denmark. The interviewees comprised three makerspace coordinators, three makerspace facilitators, two managers, and a librarian. All interviewees had experience in organizing and facilitating library makerspace activities. Each interview lasted between 45 minutes and 2.5 hours. The interviewees were asked about the activities, users, tools, community, rules, and roles that, collectively, shaped learning in the makerspaces (see Table 1). Through descriptions of concrete operations we gained insights about the interviewees' experiences, the reasoning behind the established scaffolds, and the challenges encountered.

The interviews were transcribed and coded in three rounds with Nvivo. In the first round, the transcripts were coded for the elements in the activity system: activities, tools, rules, roles, users, objective for having the makerspace, and the community in and around it (including the local community of the library). The data entities could qualify for two codes, thereby allowing us to see relations between them. By doing so, we for instance found differences among formal, nonformal and informal activities in relation to the community they serve, the rules of access, and their internal division of labor (roles). Formal, non-formal, and informal activities then became the subject of the second round of coding. In the third round of coding, quotes were selected and translated from Danish to English.

\section{RESULTS}

In this section, our results on scaffolding in formal, nonformal and informal activities are presented. Though these categories overlap, it is reflected in how library makerspaces are utilized: "We host children events in the weekends [..] Adult events are usually between five and seven so we don't intervene too much with dinner. And then the plan is to have schools and pensioners in the daytime". In other words, nonformal, family-oriented events in the weekends, non-formal or informal adult events in the evenings, and formal events for schools or other municipal organizations in the daytime.

\section{Formal Activities}

The formal activities have pre-defined learning objectives, limited temporality, pre-planned instructions and are mandatory for the students. From the library practitioners' perspective, the purpose of inviting the schools is to promote future competences to a wide audience: "The purpose is to promote some of these digital skills and reach the youth where they are. The advantage of having a class is reaching people that otherwise wouldn't come here and reach out themselves". Furthermore, as one librarian states: "I think it's good that the children come here to begin with. Maybe they even discover that the library exists". Thus, aside from the formal learning objectives, the library can promote its services to new users. We have identified three ways in which library makerspaces scaffold learning in formal learning activities:

a. Skill-driven 


\section{b. Topic-driven \\ c. Project-driven}

The skill-driven scaffolding approach is a directed approach to formal activities, in which the objective is for students to acquire a technical competence. This approach is identified in one library that aims at teaching fifth and sixth grade students entry-level programming skills and introducing them to the micro:bit. The school books and pays for the course, which is designed and taught by the library makerspace practitioners. On the first day, students are introduced to programming, the micro:bit device, and they learn to program simple things such as a digital dice. The instructional approach is that the library makerspace practitioner stands by a whiteboard and dictates what the students do. According to the library makerspace practitioner, this approach helps avoiding student mistakes: "We have found that it is much better for the children if we do it together at the blackboard. The second you hand these [instructions] out, half of the class says puff [..] Then they have no idea of what they have done or why. So we avoid that". On the second day, the students make a personalized digital watch decorated with a laser-cut frame and a selfmade strap. The watch is included in the price for the course, and therefore the students can bring it back to the school at the end of the course. In this example, the selection of the micro:bit technology and the structured instructions scaffold the learning of a technical competence.

In the topic-driven process, the objective is to have firstgrade students experience a topic in a new way. In one example, the library practitioner plans the process in collaboration with the teacher, who decides the topic, for example a book: "It is typically in Danish-classes where the class has been working with a book. When they come here they build some scenes [..] Some made fire with a fan, so it looked like flames". Like the skill-driven scaffolding approach, the course of actions is pre-planned and directed collaboratively by the teacher and library practitioner. However, in this case, it is the task of building a scene that guides the activity. The materials and technologies available shape the possibilities for action but leave considerable freedom of choice. This type of activity scaffolds a learning process that focuses on choosing materials and technologies for constructing, communicating and reflecting on a topic from a new perspective. The process is not so much about acquiring technical competences.

The project-driven scaffolding approach supports formal learning by providing access to library personnel, tools and resources. One library participates in a collaborative innovation process for high-school students with a high school, a university, and the local municipalities. The process spans several months. Each group defines their learning objective, but all groups contribute to an objective provided by the municipalities. Teachers facilitate the process, while the library makerspace provides access to technologies and expertise. The makerspace personnel provides technical support but does not control the students' innovation processes. In the end, the students present their projects publicly in the library as part of a local festival. This approach differs from the two others in duration and in its flexible learning objective. Furthermore, the role of the library makerspace is to provide technical support to projectspecific issues that come up in the process.

In each example, the conditions that guide learning differ. In the skill-driven scaffolding approach, a directed instructional method is used to scaffold the achievement of producing code and a digital watch in order to teach students a technical competence. In the topic-driven approach, the design of the task, guidance, and the materials scaffold the experience of a topic from a new perspective. In the project-driven approach, the library makerspace plays a supportive role, students can be supported on request while they learn themselves, select materials, and solve technical problems to achieve their project-specific goals.

The challenges in supporting educational processes are that formal education is a new field for library practitioners: "The most ground-breaking here is that we increasingly engage in formal learning situations. Formerly we could only do informal learning; we could not be part of anything where there were some sort grades or ECTS-points". In relation to this new role, some libraries have recruited new types of staff, including former teachers, to plan and conduct learning processes. According to one library makerspace practitioner, the educational offers are popular among schools: "We can support their teaching, We often experience that the teachers that come to us have great intentions of bringing technology into their classes but have neither the skills nor the time to do so". In other words, it is demanding in time and resources to conduct education in makerspaces, thereby making the offers popular.

In addition, the three ways of scaffolding formal activities show ambiguity with respect to who defines the learning objective, plans the activity, provides the instructions and facilitates the processes. Some libraries are eager to engage in formal education because it promotes the values of the library, allows new partnerships and supports local strategies. However, in one library, the practitioner experiences that the cost of the strategic priority of formal activities is neglecting other users: "My colleague and I discussed that we actually wished that this was a space for the citizens and not only the schools". In another library, the formal activities were even temporarily shut down because they were experienced as overly time-consuming.

\section{Non-formal Learning Activities}

Non-formal learning activities are discretionary and structured activities that take place outside formal educational institutions. Non-formal activities are popular among the libraries visited because they complement the use of the makerspace for informal activities. As one library makerspace practitioner argues: "You could think that now the doors are open and then everyone will come. But no. 
People don't. It requires a lot". In at least three of the libraries, non-formal activities have partially replaced opening hours in the informal space: "We had the space open and found that there was no user need, so to say. So we cut back on the opening hours [..] and concentrated our efforts on Saturdays where we have a dedicated family activity [..] And it has run well and we have been very busy". The nonformal activities provide structure and direction for the use of the space. This way, they can be used to reach new users, such as families. We found two ways in which non-formal activities were commonly scaffolded:

\section{a. Socially-driven \\ b. Skill-driven}

Socially-driven activities are events that aim to engage users in producing a specific object (e.g., 3D-printed jewelry, a laser-cut box or a robot) in a limited period of time. These activities usually target children and their families - or as the practitioners call them 'the engineering father'. The participation of the parent has social, collaborative as well as pragmatic aspects because the parents help ensure that their children work constructively: "Children and their parents. Only in combination as I would not like to be a kindergarten teacher". A popular non-formal activity among the makerspace practitioners is Hepocon, which is about producing a 'crappy robot' from old toys. A team of a child assisted by a parent/grandparent receives a motor and can select materials from a box of old toys to produce a robot that can battle against other robots. One library makerspace practitioner has experienced a high level of engagement from children and parents in these events: "What often happens is that the children are engaged in the beginning and, at some point, everything takes a turn toward-you can build yours and dad will build his - it's so funny (laughs)". The practitioners have designed these activities to be social, short or scalable in duration, limited by the materials in use and loosely facilitated. These activities are designed to have a low threshold for participation and to scaffold a learning experience that is engaging, social, and collaborative.

The skill-driven activities aim to support learning a technical competence that can subsequently be elaborated in informal makerspace activities or at home. These activities are usually conducted in the afternoons and structured around a specific technology such as a 3D printer, laser cutter or micro:bit. Skill-based activities are similar to the skill-driven formal activities in that they are directed by detailed instructions. The library makerspace practitioner provides an instructional design that often combines lecturing with exercises. These activities can either scaffold an introduction to a specific technology or build competences that certify users in unsupervised use of the tools in the makerspace.

The non-formal activities take place in a short period of time, are directed by the tools and materials made available, and have no formal requirements of participation. This gives relatively low barriers of entry for newcomers and can build capabilities for future uses but also involve some challenges.
For example, the limited duration of the non-formal activities, along with their focus on producing a specific (physical) object or gaining competence in a specific technology, leaves little room for exploration and creativity. Therefore, users interested in continuing their learning process must attend the informal activities or, as in one library, borrow the technology from the makerspace: "We're one of the libraries that lend micro:bit. [..] When people after 3 hours have learned to use the device, they want to learn more". Another library experimented with hosting coding camps during holidays: "It is that challenge we have on Saturdays when people drop in and disappear again. There is not much process in it. Therefore, we'd like to do clubs or trajectories where we have more of their time". Expanding the duration of the activity makes more room for combining technical skill with creative activity. In spite of the learning potential, the coding camp did not attract a critical mass of participants. Few children and families were willing to spend several days of their holiday tinkering with technology.

\section{Informal Activities}

Informal activities are the discretionary, unsupervised use of the tools in the makerspace for self-directed projects. These activities are restricted by the rules for access (opening hours, prices) and scaffold possibilities for making personal objects and learning from others, in two different ways:

\section{a. Self-directed}

\section{b. Community-based}

The self-directed activities are uses of the tools in the makerspace with the objective of making individually defined objects. The rules of the makerspace and the users' own imagination and technical skill determine the boundaries of what can be made. One practitioner kept track of users and objects. These included: "Mother making wall stickers for her children's room", "A graphic designer printing large-scale poster", "A man making t-shirts for himself and his friend to wear at their motorcycle club" and "A girl 3D-printing a horse for room decoration". In these diverse projects, the makerspace is used to decorate private rooms, make gifts for others and support hobby activities. Users can ask the library staff for an introduction to the machinery or for technical assistance in their projects. One practitioner argues that their role is to "[..] support people in their learning trajectory". The library makerspace practitioners assist users' projects if the users request help. The primary conditions limiting the informal activities are the machinery available and the rules about prices for materials, opening hours and what may be produced. For example, mass production is prohibited in most library makerspace due to unfair competition with local printing shops shops and because it is incompatible with the learning objective that legitimizes the library makerspaces: "We call it entry-level or learning makerspace. There you can only make prototypes". 
Users in community-based activities also work on their individual projects. However, community-based activities take place in the presence of other makers who contribute to social interactions and community building among the users. One practitioner tells about a frequent user, a 75-year old woman: "she drives to the junkyard and finds all sorts of trash. Then she gets a man to help her make it work, and then she draws broken parts and prints them on the 3D-printer". This example illustrates the ideal of community-based activities in which people with different backgrounds help one another make or fix products. In two of the six library makerspaces visited, the community aspect was especially appreciated. Here a community of frequent users meet once a week and this regularity strengthens the community over time. In these groups, users organized talks and field trips to local companies or other makerspaces. Compared to the selfdirected activities, the regularity of the community-based activities provides a scaffold for people to meet, interact, learn from one another, and potentially become selforganized.

Both types of informal activities have few restrictions on access to the space and what objects that may be produced. However, there are challenges. First, self-directedness is required, as one library practitioner explains: "Not everyone can manage self-initiation and if not, you don't fit too well in here". Not all users have the technical skills and conceptual abilities to define a project and guide their process. Though some of the makerspaces have instructions to get people started and technical assistance to reach specific goals, there is little support for users that do not have a project in mind when they enter the informal space.

In the community-based library makerspace, it is a challenge to ensure inclusivity and heterogeneity in the community. According to one practitioner, her community of users consisted primarily of technically skilled men. This community had a high degree of engagement, selforganization, and ownership of the space. However, another practitioner explains, that ownership can be at the cost of inclusion: "It's really positive that someone takes ownership, but they must not feel that they own the place. We'd like to continue having open doors so everyone can feel they are welcome and that it's not a closed club". That is, too much ownership by regular users may raise the social barriers for participation for new users. Additionally, he argues, that it is the library's responsibility to ensure that the community is inclusive.

\section{DISCUSSION}

In our results, we have described formal, non-formal, and informal activities in library makerspaces and identified their approaches and techniques to scaffold different objectives (summarized in Table 2). In the following, we briefly compare their scaffolding approaches and discuss three challenges in library makerspaces: inviting new users while sustaining a community, avoiding to stifle creativity in short-

\begin{tabular}{|c|c|c|}
\hline Activity & Scaffolding approach & Objective \\
\hline \multirow{3}{*}{$\begin{array}{l}\text { Formal } \\
\text { activities: } \\
\text { Pre-planned } \\
\text { Mandatory }\end{array}$} & $\begin{array}{l}\text { Skill-driven: activity } \\
\text { planning, lecturing, } \\
\text { guidance }\end{array}$ & $\begin{array}{l}\text { Acquisition of } \\
\text { competence }\end{array}$ \\
\hline & $\begin{array}{l}\text { Topic-driven: activity } \\
\text { planning, material } \\
\text { selection, guidance }\end{array}$ & $\begin{array}{l}\text { New perspective } \\
\text { to explore a } \\
\text { topic/theme }\end{array}$ \\
\hline & $\begin{array}{l}\text { Project-based: access to } \\
\text { tools, guidance on request }\end{array}$ & Project-specific \\
\hline \multirow{2}{*}{$\begin{array}{l}\text { Non-formal } \\
\text { activities: } \\
\text { Pre-planned } \\
\text { Discretionary }\end{array}$} & $\begin{array}{l}\text { Socially-driven: activity } \\
\text { planning, material } \\
\text { selection, guidance on } \\
\text { request }\end{array}$ & $\begin{array}{l}\text { Social relation } \\
\text { Engagement }\end{array}$ \\
\hline & $\begin{array}{l}\text { Skill-driven: activity } \\
\text { planning, lecturing, } \\
\text { guidance }\end{array}$ & $\begin{array}{l}\text { Acquisition of } \\
\text { competence } \\
\text { Recruitment of } \\
\text { users }\end{array}$ \\
\hline \multirow{2}{*}{$\begin{array}{l}\text { Informal } \\
\text { activities: } \\
\text { Discretionary } \\
\text { Unsupervised } \\
\text { Self-directed } \\
\text { Rules of access }\end{array}$} & $\begin{array}{l}\text { Self-directed: rules, } \\
\text { opening hours, guidance on } \\
\text { request }\end{array}$ & Project-specific \\
\hline & $\begin{array}{l}\text { Community-based: access } \\
\text { to tools, guidance on } \\
\text { request, peer support, } \\
\text { community hours }\end{array}$ & $\begin{array}{l}\text { Project-specific } \\
\text { Social }\end{array}$ \\
\hline
\end{tabular}

Table 2. Formal, non-formal, and informal activities

term activities, and the division of labor between school and library.

Skill-driven and topic-driven formal activities are mandatory, take place in a short period of time, use selected tools and materials, and have activity designs that guide the course of actions and configure and discipline the activity [20]. These conditions scaffold learning towards pre-defined objectives whether it is understanding a topic, making a concrete artifact or training a specific technical competence. In the non-formal activities outside formal educational contexts, we find similar directed techniques being used with a broader audience. Thus, in spite of the similarity in directedness, these scaffolding approaches differ in the role of the tools. In the socially-driven and topic-driven activities, the tools and materials are scaffolds for collaboration, engagement or seeing a topic from a new perspective. The tools are means to an end, while in the skill-driven activities, mastering the tools is the end itself.

Formal and informal activities also overlap in library makerspaces. For instance, the project-based formal learning has informal attributes as the students themselves define objectives, select materials, and are self-directed in their process. In these learning processes, the library scaffolds learning by taking the role of a resource. By allowing undirected access to tools and materials, and assisting projects on request, the library maker space can scaffold learning towards individual objectives. In the informal activities, there are few restrictions other than those inherent in the available tools. The rules for using the spaces prohibit some activities, but the main restriction is, probably, the 
users' drive and imagination. In the community-based informal activities, we see that adding simple temporal regularities can provide the additional scaffolding necessary for fostering a community of users.

\section{Challenges}

Inviting new users while sustaining a community: The library makerspaces visited acknowledge that offering informal activities is insufficient for utilizing the potential of the makerspaces. As a result, staff had in two cases been relocated from informal activities to the planning and execution of non-formal activities. Possible explanations for the limited use of the informal activities can be that the technical appearance of the space may be intimidating [10], that the information on the possible uses of the space is insufficient [2] and - as one interviewee argued - that the required self-initiation is not for everyone. Similar to Taylor et al. [24], there are also social barriers for new users entering the informal space. These barriers are especially apparent in the makerspaces that are successful in facilitating community-based activities with many regulars. Over time the community takes ownership and develops norms and informal rules about how to behave, thereby creating social barriers for newcomers. The libraries have different approaches to balancing the entry of new users against the communities of regulars. If libraries wish to be promoters of equitable access to information and resources [9] then they must assume responsibility for scaffolding the entry of new users, while sustaining the community qualities appreciated by the regulars.

Avoiding to stifle creativity in short-term activities: A frequently used scaffold to engage new users is hosting short-term activities [10,24]. We have found such activities in both formal and informal contexts. These activities are structured by a short time span and restricted in material and tools in order to support learning of a pre-defined objective. In these activities, some pedagogical challenges need to be considered. Blikstein [4], for example, describes the challenge of the 'keychain syndrome' where facilitators can be tempted to instruct users in making aesthetically pleasing products that require little effort, at the cost that the users do not go through a challenging learning cycle. Highly directed skill-driven activities where operations are dictated by an instructor run the risk of falling into this trap. Activities such as social non-formal activities and topic-driven formal activities allow more freedom for learning by designing, experimenting, and iterating. In formal activities, educators can encourage more complicated projects [6] or motivate longer timescales [25]. In non-formal activities, our results indicate that the keychain syndrome is difficult to overcome due to the scarcity of leisure time. Other than the skill-driven scaffolding approach, few non-formal activities succeed in creating a transition to informal activities. One approach to overcome this challenge, is to take a project-based approach $[4,25]$. Non-formal activities could be designed to ideate and initiate projects, that could be continue informally in the makerspace. In this way, the non-formal activity acts as a scaffold towards a longer self-directed learning process.

Division of labor between school and library makerspace: Lastly, we find that the library makerspace practitioners engage in formal education and experience this engagement as a novel task. Without educational training they are challenged when faced with planning and conducting teaching sessions [4], with aligning maker activities with formal educational curriculums $[4,17]$, and with finding the time necessary for preparations [26]. In our interviews, we found that the division of labor between teacher and library makerspace practitioner is not clear. The library practitioner can be the primary educator, a collaborator along with the teacher or a technical resource to schools. Though it is dependent on the local interests and capacity, the relation between library makerspace and formal education is highly relevant to address in Denmark, because makerspaces as well as education in computational thinking are being implemented in schools on a national scale [26]. Whether libraries should be central makerspace hubs with advanced tools, supporting teachers' skill development, or take an active role in the formal education of children is a question yet to be answered.

\section{Limitations}

Limited empirical material: This paper is based on interviews with nine representatives from six Danish libraries. The sample is not sufficient to generalize in or outside of Denmark, nor give a complete view of all activities and approaches to scaffolding. In future work we will extend the findings from this study into a mapping of how formal, non-formal, and informal learning activities are scaffolded in Danish library makerspaces.

Practitioners' point of view: This research aims to capture the library makerspace practitioners' perspective on how they scaffold learning in library makerspaces. We are aware that the intended learning objectives may differ from the actual learning outcomes [16]. It is for future studies to compare the intentions identified in this study with the actual learning of students, participants, and users.

\section{CONCLUSION}

In this paper, we have explored the questions how learning is scaffolded and what challenges library makerspace practitioners experience in scaffolding learning activities. We found seven different approaches to scaffolding in formal, non-formal, and informal activities. These approaches have their individual challenges including ensuring the inclusion of new users, avoiding to stifle creativity in short-term activities, and defining the role of the library in educational activities. To overcome these challenges, we argue for attending to the balance between strong community and easy access of new people, for the design of non-formal activities that can scaffold use in informal activities, and for clarifying the role of the library makerspace in formal educational activities. 


\section{REFERENCES}

1. Shannon C. Barniskis. 2016. Access and express: Professional perspectives on public library makerspaces and intellectual freedom. Public Library Quarterly 35, 2: $103-125$.

2. Shannon C. Barniskis. 2016. Creating space: The impacts of spatial Arrangements in public library makerspaces. In IFLA WLIC 2016. 1-10.

3. Ann Blandford, Dominic Furniss, and Stephann Makri. 2016. Qualitative HCI research: Going behind the scenes. Synthesis Lectures on Human-Centered Informatics 9, 1: 1-115.

4. Paulo Blikstein. 2013. Digital fabrication and 'making' in education: The democratization of invention. FabLabs: Of machines, makers and inventors 4: 1-21.

5. Christian Born, Maria Henkel, and Agnes Mainka. 2018. How public libraries are keeping pace with the times: Core services of libraries in informational world cities. Libri 68, 3: 181-203.

6. Leanne Bowler. 2014. Creativity through "Maker" experiences and design thinking in the education of librarians. Knowledge Quest 42, 5: 58-61.

7. Leanne Bowler and Ryan Champagne. 2016. Mindful makers: Question prompts to help guide young peoples' critical technical practices in maker spaces in libraries, museums, and community-based youth organizations. Library \& Information Science Research 38, 2: $117-$ 124.

8. Tara Brady, Camille Salas, Ayah Nuriddin, Walter Rodgers, and Mega Subramaniam. 2014. MakeAbility: Creating accessible makerspace events in a public library. Public Library Quarterly 33, 4: 330-347.

9. Patrick T. Colegrove. 2017. Makerspaces in libraries. In Encyclopedia of Library and Information Sciences. CRC Press, 2990-2996.

10. Katrien Dreessen and Selina Schepers. 2018. Three strategies for engaging non-experts in a FabLab. In Proceedings of the 10th Nordic Conference on HumanComputer Interaction (NordiCHI '18), 482-493.

11. Agnes Erich. 2018. The role of public libraries in nonformal learning. Revista Romaneasca Pentru Educatie Multidimensionala 10, 3: 17-24.

12. Erica Halverson, Alexandra Lakind, and Rebekah Willett. 2017. The Bubbler as systemwide makerspace: A design case of how making became a core service of the public libraries. International Journal of Designs for Learning 8, 1: 57-68.

13. Erica Halverson and Kimberly Sheridan. 2014. The Maker Movement in education. Harvard Educational Review 84, 4: 495-504.

14. Mark Hatch. 2014. The maker movement manifesto: Rules for innovation in the new world of crafters, hackers, and tinkerers. McGraw-Hill Education, New York.

15. Casper H. Rasmussen. 2016. The participatory public library: the Nordic experience. New Library World 117 , 9/10: 546-556.
16. David H. Jonassen and Lucia Rohrer-Murphy. 1999. Activity theory as a framework for designing constructivist learning environments. Educational Technology Research and Development 47, 1: 61-79.

17. Denise Lindstrom, Ann D. Thompson, and Denise A. Schmidt-Crawford. 2017. The Maker Movement: Democratizing STEM education and empowering learners to shape their world. Journal of Digital Learning in Teacher Education 33, 3: 89-90.

18. Janice Malcolm, Phil Hodkinson, and Helen Colley. 2003. The interrelationships between informal and formal learning. Journal of workplace learning 15, 7/8: 313-318.

19. Heather Moorefield-Lang. 2018. Lessons learned: intentional implementation of second makerspaces. Reference Services Review.

20. Wanda J. Orlikowski. 2006. Material knowing: The scaffolding of human knowledgeability. European Journal of Information Systems 15, 5: 460-466.

21. Daniel Schugurensky. 2006. This is our school of citizenship: Informal learning in local democracy. In Learning in Places - The Informal Educational Reader. Peter Lang, New York, 163-182.

22. Nina Simon. 2010. The Participatory Museum. Museum 2.0.

23. Diane Slatter and Zaana Howard. 2013. A place to make, hack, and learn: Makerspaces in Australian public libraries. The Australian Library Journal 62, 4: 272284.

24. Nick Taylor, Ursula Hurley, and Philip Connolly. 2016. Making community: The wider role of makerspaces in public life. In Proceedings of the 2016 CHI Conference on Human Factors in Computing Systems, 1415-1425.

25. Sawaros Thanapornsangsuth. 2016. Using Humancentered design and social inventions to find the purposes in making. In Proceedings of the 6th Annual Conference on Creativity and Fabrication in Education, 17-25.

26. Ari Tuhkala, Marie-Louise Wagner, Nick Nielsen, Ole S. Iversen, and Tommi Kärkkäinen. 2018. Technology Comprehension: Scaling making into a national discipline. In Proceedings of the Conference on Creativity and Making in Education, 72-80.

27. Lev S. Vygotsky. 1980. Mind in society: The development of higher psychological processes. Harvard university press.

28. Rebekah Willett. 2016. Making, makers, and makerspaces: A discourse analysis of professional journal Articles and blog posts about makerspaces in Public Libraries. The Library Quarterly 86, 3: 313-329.

29. Rebekah Willett. 2018. Learning through making in public libraries: Theories, practices, and tensions. Learning, Media and Technology 43, 3: 250-262.

30. Theresa Willingham and Jeroen De Boer. 2015. Makerspaces in libraries. Rowman \& Littlefield. 